\title{
Facets of Mindfulness in Stages of Behavior Change Toward Organic Food Consumption
}

\author{
Nadine Richter $^{1}$ (D) Marcel Hunecke $^{1}$
}

Published online: 2 April 2020

(C) The Author(s) 2020

\begin{abstract}
Objectives The preference of organically grown foods can potentially decrease greenhouse gas emissions, which are related to climate change. Recent empirical studies suggest associations between dispositional mindfulness and self-reported pro-environmental behavior. In order to identify the potential and mechanisms of mindfulness with regard to pro-environmental behaviors, it is necessary to consider theories of action.

Methods The present study examines the relationship between five facets of self-attributed mindfulness and organic food consumption considering a stage model of behavior change that includes different types of intentions and stage-specific predictors adapted from the theory of planned behavior and the norm-activation model. A cross-sectional online study was conducted with a sample of 560 participants. The mean age of the participants was $30(S D=10.5)$ years, and the sample consisted largely of females $(76 \%)$. A minority reported regular meditation practice (8\%).

Results The multivariate analyses showed a significant relationship between observing and goal intention $(\beta=.317, p<.000)$ as well as the indirect effects of observing on goal intention that is mediated by personal norms and attitude. Further, people in the postaction stage have higher levels of observing than those in the predecision stage ( $p=.003, d=.43$ ). Overall, the mindfulness facets contribute low to the explained variance of the stage model variables.

Conclusion Consistent across the analyses, the mindfulness facet of observing was proved to be a particularly relevant predictor of organic food consumption-related variables. The investigation of the observing facet could be beneficial to understand associated mechanisms and starting points to promote pro-environmental behavior through mindfulness.
\end{abstract}

Keywords Sustainability $\cdot$ Mindfulness $\cdot$ Pro-environmental behavior $\cdot$ Organic food consumption $\cdot$ Structural equations

There is broad scientific consensus on the prevalence of human-caused climate change (Cook et al. 2016). Particularly, the emission of greenhouse gases (GHGs) such as $\mathrm{CO}_{2}$ in the atmosphere has been on the rise compared to pre-industrial times. The consequences are global warming, rapid extinction of species, periods of drought, and extreme weather phenomena (Pachauri and Mayer 2015). The mitigation of GHG is necessary to limit these adverse effects on

Electronic supplementary material The online version of this article (https://doi.org/10.1007/s12671-020-01351-4 ) contains supplementary material, which is available to authorized users.

Nadine Richter

nadine.richter@fh-dortmund.de

1 Present address: Faculty of Applied Social Sciences, University of Applied Sciences and Arts Dortmund, Emil-Figge-Str. 44, 44227 Dortmund, Germany nature and humans. One mitigation potential is in the food sector; the production and consumption of food contribute up to one-third of the worldwide GHG emissions (Vermeulen et al. 2012). Besides policies for more sustainable production, individual behavior changes in food consumption are required (Reisch et al. 2013). Sustainable forms of nutrition include the reduction of meat consumption as well as the preference of regional, seasonal, and organically grown foods (Von Koerber et al. 2017). In addition to the reduction of GHG emission, organic agriculture has the potential to enhance biodiversity (Bengstsson et al. 2005; Scialabba and MüllerLindenlauf 2010).

The concept of mindfulness has been discussed recently in terms of its potential to contribute to a sustainable lifestyle (Ericson et al. 2014; Hunecke 2013) and sustainable consumption behavior (Bahl et al. 2016; Fischer et al. 2017; Rosenberg 2004). Mindfulness is often defined as nonjudgmental awareness, which is characterized by paying 
attention on purpose and being anchored in the present moment (Kabat-Zinn 1990). A growing number of empirical studies found dispositional mindfulness to be correlated with self-reported pro-environmental behaviors (Amel et al. 2009; Brown and Kasser 2005; Geiger et al. 2018a; Jacob et al. 2009). Based on a review of 12 correlational empirical studies, Geiger et al. (2018a) suggested five potential pathways from mindfulness to ecological consumption: (1) disruption of routines; (2) congruence of attitude and behavior; (3) prosociality and connectedness to nature and others; (4) [nonmaterial] values and meaning in life; (5) personal health and [subjective] well-being. From a theoretical perspective, Hunecke (2018) derived two further pathways that have not yet been empirically investigated. The first is the sensitization through mindfulness for one's body and sensory perception. Some studies suggest that mindfulness heightens the enjoyment experienced while eating (Hong et al. 2014) and prevents overconsumption (Arch et al. 2016). Mindfulness can help people enjoy experiences more intensely and, subsequently, lower the frequency and amount of consumption. The second further possible pathway from mindfulness to a more sustainable lifestlye is through self-esteem. Mindfulness is associated with higher self-esteem (Pepping et al. 2013), and a stable self-esteem can prevent people from compensatory forms of materialistic consumerism (Kasser 2006; Sivanathan and Pettit 2010).

Previous studies and theoretical considerations suggest that mindfulness is not a direct but distal predictor of proenvironmental behavior. Some of the mediators between mindfulness and pro-environmental behavior that have been already identified are connectedness to nature (Barbaro and Pickett 2016; Wang et al. 2019), health behavior (Geiger et al. 2018b), social dominance orientation (Panno et al. 2018), and the construction of meaning (Hunecke and Richter 2019). Although previous studies show small to moderate positive relationships between mindfulness and self-reported pro-environmental behaviors, an integration of the predictors of action theories is required, which are used to explain environmental behavior. First, the consideration of these variables is necessary to explore the predictive value of mindfulness compared to the established variables. Second, to adequate plan and evaluate mindfulness-based programs (MBPs) to promote pro-environmental behaviors, a differentiated examination of mindfulness and action theory-based variables is required.

An integration of the essential predictors of proenvironmental behaviors was done by Bamberg et al. (2011) in the stage model of self-regulated behavior change (SSBC) which was further developed and empirically validated by Bamberg $(2013 \mathrm{a}, \mathrm{b})$. It combines the most important variables of the theory of planned behavior (TPB) (Ajzen 1991), the norm-activation model (NAM) (Schwartz 1977), and stages of action (Gollwitzer 1990). Additional to the variables adapted from the TPB and NAM, the model consists of four different stages of action, three different intentions, and the target behavior. According to the TPB, an intention is the most central and direct predictor of a behavior. It is influenced by social norms, the attitude toward the behavior, and the perceived behavior control regarding the behavior. In contrast, the NAM considers the personal norm as the strongest predictor of behavior. The personal norm refers to a moral obligation to behave in a certain way, and it is especially driven by perceived responsibility and the awareness of the consequences of one's behavior.

The SSBC proposes four stages of behavioral action that are adapted from the mindset theory of action phases (MAP) (Gollwitzer 1990): (1) predecision: people in this stage have no problem awareness of environmentally harmful behavior and no intention to change their behavior; (2) preaction: in this stage, people are aware that a change in their behavior is needed but have no concrete plans on how to implement this change; (3) action: people in this stage have planned when and how to change their current behavior and take the first steps toward their new behavior; (4) postaction: in this stage, people have changed their behavior into a new habit. Transition from one stage to the next is marked by three different types of intentions. The goal intention marks the behavior change as a general goal, and it is formed by the evaluation of the negative consequences associated with the current behavior as well as the perceived responsibility for reducing these negative consequences. This evaluation is motivated by personal and social norms, goal feasibility, perceived feasibility, responsibility, negative consequences, and emotions. The behavior intention relates to the intention to pursue the concrete behavior and is influenced by the perceived behavior control and attitude toward the specific behavior. The implementation intention includes concrete plans to pursue the target behavior on the next possibility and represents the last step before the implementation of the new habit. For a strong implementation intention, competencies such as the ability to pursue the behavior despite the perceived barriers (maintenance selfefficacy) as well as cognitions and action planning are relevant. Once people establish the new habit, the ability to recover from a relapse is important for the maintenance of the new behavior (recovery self-efficacy). The SSBC has been successfully applied to explain car use and create interventions to reduce car usage (Bamberg 2013a) and meat consumption (Klöckner 2017). Regarding the consumption of organically grown food, studies show that social and personal norms, attitude, perceived behavior control, intention, values, and ecological concerns are important predictors (Aertsens et al. 2009; Scalco et al. 2017).

The main elements of mindfulness can be summarized as follows. The first element is the self-regulation of attention, which includes the ability to sustain and switch attentional focus. Further, while being mindful, all emerging experiences are perceived with an open and accepting attitude (Bishop 
2004). A distinction can be made between mindfulness as a dispositional trait, often measured through self-reports, and the practice of mindfulness, which includes sitting meditation or body-orientated meditation forms such as mindful walking. While some studies have found an increase in dispositional mindfulness through MBPs (Kiken et al. 2015), a metaanalysis found that not all MBPs enhance self-reported dispositional mindfulness, highlighting the difficulties in assessing the experiences of mindfulness practices with self-reports (Visted et al. 2015). One widely used instrument to assess mindfulness by self-report is the Five Facet Mindfulness Questionnaire (FFMQ) (Baer et al. 2008). The FFMQ includes five dimensions: (1) observing, which is described as the awareness of the experience of inner and outer stimuli such as sensations, cognitions, emotions, sights, sounds, and smells, (2) nonreactivity, which is defined as the ability to allow thoughts and feelings to come and go without getting caught up in them, (3) acting with awareness, which is defined as conscious attention and awareness toward one's actions and is often described as "leaving the automatic pilot," (4) nonjudging, which implies a non-judgmental attitude toward thoughts and feelings, and lastly, (5) describing, which includes the ability to label internal experiences with words (Baer et al. 2008). The validity of the FFMQ has been tested among samples with and without meditation experience (de Bruin et al. 2012).

With the explicit goal to promote pro-environmental behaviors, MBPs are, with a few exceptions, seldom applied and examined (Barrett et al. 2016; Geiger et al. 2019). Also, some successful trainings were developed to foster healthy eating behavior, indicating connections between mindfulness and changes in food consumption behavior (Kristeller et al. 2014). Previous studies have suggested that different dispositional mindfulness aspects vary in their relationship with selfreported pro-environmental behavior (Amel et al. 2009; Barbaro and Pickett 2016; Geiger et al. 2018b; Hunecke and Richter 2019).

The mindfulness aspect of observing is one of the most essential aspects of mindfulness (Lilja et al. 2013). Observing has been consistently found to be moderately correlated with pro-environmental behaviors $(r=.20)$ (Geiger et al. 2018a). Observing is a central mechanism of perception and awareness, and it provides a basis for further reflective processes and building up intentions or behavioral actions. Owing to this basic perceptive function of observing, relationships of observing with stage-specific variables, different types of intentions, and organic food consumption are conceivable. Consequently, higher scores of observing can be expected in members of the postaction stage compared to members of all other stages.

Several studies have found the aspect of acting with awareness to be correlated with self-reported pro-environmental behavior (Amel et al. 2009; Barbaro and Pickett 2016; Brown and Kasser 2005; Panno et al. 2018). The bivariate correlations vary from weak to moderate effect sizes. However, other studies have not found such a relationship (Barbaro and Pickett 2016; Geiger et al. 2018b). Acting with awareness is the aspect of dispositional mindfulness that is closest to actual behavior, as it refers to heighted attention toward one's actions. With regard to food consumption, acting with awareness might support carrying out the intended behavior, instead of habitual acting. Moreover, situational awareness might be linked to a subjective feeling of control over one's behavior. Therefore, a positive relationship between acting with awareness and perceived behavior control and organic food consumption is possible. Consequently, higher means of acting with arwareness can be expected in members of the postaction stage in comparison to those in preaction stages.

Some studies have found weak but statistically significant correlations between nonreactivity and pro-environmental behavior (Barbaro and Pickett 2016; Geiger et al. 2018b). A high level of nonreactivity might help to resist temptations and allow cognitions and emotions to roll past. This mechanism is discussed in terms of the prevention of impulsive buying (Park and Dhandra 2017) and impulsive eating behaviors (Papies et al. 2012). Hence, people with high nonreactivity may be able to regulate sucessfully the impulses that distract the implementation processes and maintenance of a certain behavior. The feeling of control over one's behavior might complement the ability of self-regulation. Therefore, nonreactivity might be connected to perceived behavior control, the implementation intention, and organic food consumption behavior. In line with this, members of the action and postaction stages may score higher on nonreactivity than those in the predecision and preaction stages.

The dimension of describing pertains to the ability to put experiences into words. Some studies that included this dimension found weak significant correlations between describing and pro-environmental behaviors (Barbaro and Pickett 2016; Geiger et al. 2018b; Hunecke and Richter 2019). The ability to describe one's experiences is crucial for constructive reflection on one's goals in life. Therefore, describing might be relevant in the preactional stages and therefore related to the associated intentions, particularly goal intention and behavior intention as well as the stage-specific predictors personal norms, attitude, and perceived behavior control. People in the stages of action and postaction may have a higher level of describing than those in the other stages, as they have already successfully created a behavior intention and passed the stages of predecision and preaction.

Lastly, the aspect of non-judging, which comprises maintaining a non-evaluative stance toward one's thoughts and feelings (Baer et al. 2006), has shown no significant correlation with pro-environmental behavior in previous studies. Not to judge experiences is sometimes considered as a mechanism that further goes along with a non-striving accepting stance 
toward emerging thoughts and feelings (Shapiro et al. 2006). It is not conceivable that a non-judging stance is positively related to any intention or intentional behaviors, as it is hard to engage in reflective processes or develop intentions when not evaluating cognitions and feelings.

To examine the identified potential correlations between the different mindfulness dimensions and organic food consumption, we suggested a theoretical model based on the SSBC (see Fig. 1) and addressed the following research questions: Q1: Which mindfulness dimensions show a relationship with the intentions (goal-, behavior-, and implementation intention) and self-reported organic food consumption? Q1.1: Do these relationships remain when stage-specific variables (social norms, personal norms, attitude, and perceived behavior control) are included? Q2: Are there relationships between the mindfulness dimensions and the stage-specific variables? Q2.1: Are there significant indirect effects of the mindfulness dimensions on the intentions and behavior, mediated by stagespecific variables? Q3: Are there differences between people in the stages of behavior change regarding the mindfulness dimensions of the FFMQ?

\section{Method}

\section{Participants}

Out of 610 largely completed surveys, 567 participants correctly passed the two quality-check items. Since structural equation modeling ideally requires complete data, we excluded seven cases that had missing values on relevant measures. Finally, 560 cases remained for the analyses. An a priori power analysis, using G*Power (Faul et al. 2007), suggested that a sample size of at least 492 is required to reveal a medium size effect regarding the mean differences between the stages $\left(f^{2}=\right.$ $0.15, \alpha=0.05,1-\beta=0.80$ ).
The mean age of the participants was $30(\mathrm{SD}=10.5)$. The educational degree was high, and most of the participants worked in a full-time $(29.5 \%)$ or half-time $(16.5 \%)$ occupation. About one-third of the participants were undergraduate students (36.1\%). Most (55\%) lived in a city with a population of over 100,000 people. The proportion of people with vegan $(6.4 \%)$ and vegetarian $(16.1 \%)$ diets was high compared to the German population, but the majority reported an omnivore diet $(72.4 \%)$. Few participants reported a diet with fish but without meat (3.2\%). Almost half participants (43.6\%) had no experience with meditation (e.g., vipassana) or meditative bodywork (e.g., yoga). The other half reported experience but no regular meditation practice $(48.4 \%)$, while a minority stated that they practiced at least once a week $(8 \%)$ (see demographic characteristics in Table 1).

\section{Procedure}

Data collection was done through an online survey using the software Qualtrics. The survey invitation was spread in different online communities with and without relation to the topics of food to ensure enough participants in every stage of action. As compensation, the participants were offered to participate in a lottery of $25 \times 20$ Euro Amazon and $50 \times 10$ Euro drugstore vouchers.

\section{Measures}

Mindfulness Mindfulness was assessed through a shortened version of the German version of the FFMQ (Michalak et al. 2016). The shortened version contained four items for each dimension, and their psychometric properties had been proofed in a previous study (Hunecke and Richter 2019).

Stage Model To adapt the model to the purpose of our study, we modified the SSBC by Bamberg (2013b) at two points.

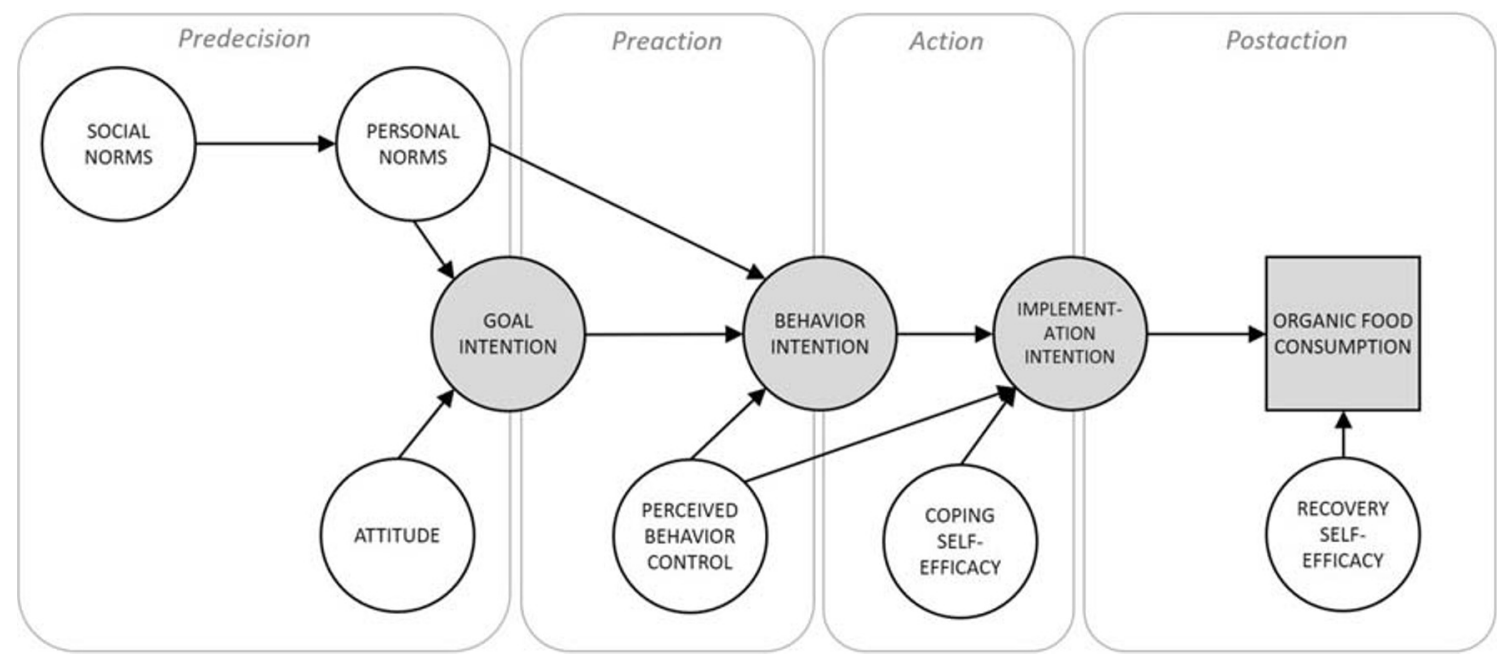

Fig. 1 Theoretical model 
Table 1 Demographic characteristics of the sample $(N=$ 560)

\begin{tabular}{|c|c|c|c|c|}
\hline & $M(\mathrm{SD})$ & Categories & $n$ & $\%$ \\
\hline \multirow[t]{2}{*}{ Age (years) } & $30(10.5)$ & & & \\
\hline & & Not specified & 2 & \\
\hline \multirow{2}{*}{$\begin{array}{l}\text { Monthly net income } \\
\text { per person (Euro) }\end{array}$} & $1182.20(719.23)$ & & & \\
\hline & & Not specified & 266 & 47.5 \\
\hline \multicolumn{5}{|l|}{ Gender/sex } \\
\hline & & Female & 423 & 75.5 \\
\hline & & Male & 132 & 23.6 \\
\hline & & Other & 5 & 0.9 \\
\hline \multicolumn{5}{|l|}{ Education } \\
\hline & & No degree (or not yet) & 3 & 0.5 \\
\hline & & Elementary school & 1 & 0.2 \\
\hline & & Main school & 13 & 2.3 \\
\hline & & Middle school & 63 & 11.3 \\
\hline & & Higher education entrance qualification & 241 & 43.0 \\
\hline & & University degree & 239 & 42.7 \\
\hline \multicolumn{5}{|l|}{ Occupation } \\
\hline & & Pupil & 11 & 2.0 \\
\hline & & Vocational training & 32 & 5.7 \\
\hline & & Undergraduate student & 202 & 36.0 \\
\hline & & Full-time employee & 165 & 29.5 \\
\hline & & Part-time employee & 92 & 16.4 \\
\hline & & Unemployed & 43 & 7.7 \\
\hline & & Other & 14 & 2.5 \\
\hline & & Not specified & 1 & 0.2 \\
\hline \multicolumn{5}{|l|}{ Place of birth } \\
\hline & & Germany & 502 & 89.6 \\
\hline & & Other & 56 & 10.0 \\
\hline & & Not specified & 2 & 0.4 \\
\hline
\end{tabular}

First, we only included the most important predictors for organic food consumption. Second, we considered attitude as a predictor of the goal intention, instead of the behavior intention. Previous applications of the stage model distinguished between a general goal (e.g., reduce car use) and the different behavior strategies to achieve this goal (e.g., take the bus or the bicycle). As the focus of the present study is on one single behavior strategy and the general goal the preference of organic food, we considered the attitude as a preliminary predictor of the goal intention. In the following, the term "stage variables" denotes all psychological constructs in the stage model, including the different types of intentions and their predictors as well as behavior. The term "stage-specific variables" refers to predictors of the intentions and the behavior, namely the social and personal norms, attitude, perceived behavior control, and self-efficacy variables. "Stage" refers to the action phases wherein people can be categorized. Figure 1 shows the theoretical model applied in this study. The items of the variables of the stage model were formulated based on Bamberg (2013b) and Klöckner (2017) and adjusted to organic food consumption. The different intentions (goal intention, behavior intention, and implementation intention) were assessed with two items each (5-point scale from 1 "does not apply" to 5 "fully applies"). As predictors of the different intentions, the following variables were included with each two items (5-point scale from 1 "very easy" to 5 "very difficult"): personal and social norms, attitude, maintenance selfefficacy, recovery self-efficacy, and perceived behavior control. To ensure consistency, the items for maintenance and recovery self-efficacy were not presented to the participants who stated having no behavior intention.

A categorical instrument with four statements was used to identify stage membership: (1) Currently, I mostly buy conventionally produced food and do not intend to change this in the future. (2) Currently, I am thinking about buying organically produced food more frequently instead of conventionally produced food, but I am not yet sure how I can realize it. (3) I intend to buy organically produced food more frequently, and I have already informed myself about how I can realize it. (4) I already prefer buying organically produced food as often as 
possible instead of conventionally produced food, and I intend to maintain this in the future. (5) For me, none of the statements applies, as in my household I am not responsible for buying food. In the original instrument by Bamberg (2013a), the first stage is assesed by two statements, and their selection lead to the classification into the predecision stage. As both statements lead to the same classification, we summarized them and present only one statement, which covers the stage of predecision, where people have no intention to change their behavior. Participants who reported no responsibility for buying food in their household (statement five) were excluded from the rest of the survey.

Organic food consumption was measured through seven questions covering different types of food (e.g., vegetables and fruits, dairy products, meat and fish, drinks, sweets, and staple foods). The participants were asked how often they buy these products in organic quality (5-point scale from 1 "never," to 5 "always").

\section{Data Analysis}

The analysis of the data was done in $\mathrm{R}$ version 3.4.3. The means of all stage variables were compared across the different stage groups using ANOVA and post hoc tests with Bonferroni correction to test the plausibility of the stage model. Variance homogeneity was tested in advance using a Levene test. The fit of the basic stage model (model 1, see Fig. 2) was tested through a structural equation model (SEM) using the $\mathrm{R}$ package lavaan. The multivariate normal distribution was tested with the package MVN. A confirmatory factor analysis (CFA) was done to proof the factor structure of the mindfulness dimensions. The model fit for the CFA and SEM was evaluated by looking at the comparative fit index (CFI), Tucker-Lewis index, root mean square error of approximation
(RMSEA), and the standardized root mean square residual (SRMR). CFI and TLI of $\geq .95$, an RMSEA, and an SRMR of $\leq .08$ indicated an acceptable fit (Hu and Bentler 1999). As the data were not multivariate normal distributed, the maximum likelihood estimation was applied with the SatorraBentler correction for the test statistics. The significance of the indirect effects was tested with bootstrapping $(N=5.000)$ and the estimation of $95 \%$ bias-adjusted percentile (asymmetric) confidence intervals.

Addressing Q1 and Q2, the relationships between the five mindfulness dimensions, intentions, organic food consumption, and stage-specific variables were explored with SEM by the following steps: First, a reduced stage model only with the three intentions, organic food consumption behavior and with the mindfulness facets as predictors of those (model 2, see figure in supplementary materials). Second, an extended stage model with the mindfulness facets as predictors for intention and behavior to test whether the relationships between mindfulness, itentions, and behavior remain stable when the complete basic stage model is included (model 3, see Fig. 3). Third, an extended stage model with the mindfulness facets as predictors of the stage-specific variables (model 4, see Fig. 4). Addressing Q3, the mindfulness mean differences of the members of the stages groups were examined using an ANOVA.

\section{Results}

\section{Plausibility of the Stage Model}

Overall, the means of the stage variables were as expected: the higher the stage, the higher the means (see Table 2). Only perceived behavior control differed slightly from this pattern. As the items on the self-efficacy scales were only presented to

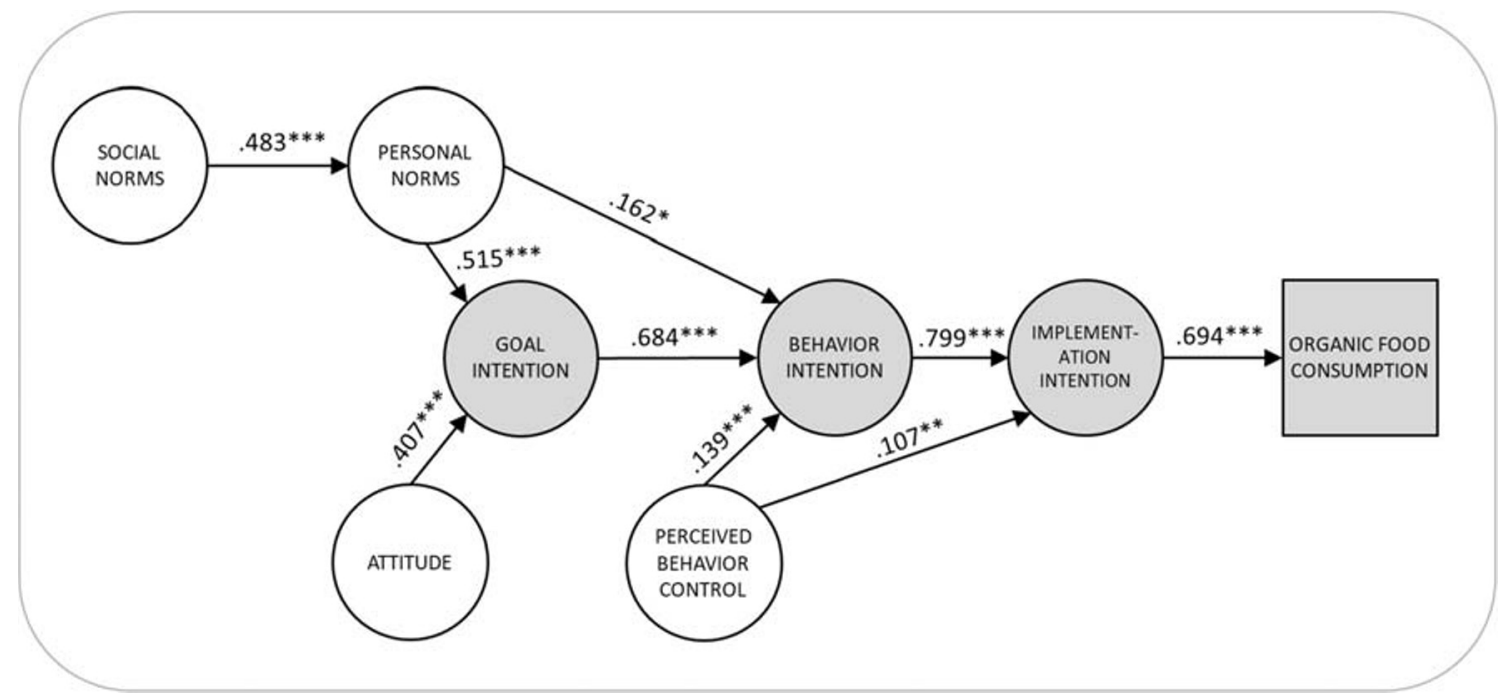

Fig. 2 Model 1: basic stage model. Note. Completely standardized coefficients. * $p<.05 ; * * p<.01 ; * * * p<.001 ; N=560$; model fit (Satorra-Bentler correction): $\chi^{2}(77)=185.907, p<.000 ; \mathrm{CFI}=.979, \mathrm{TLI}=.971, \mathrm{RMSEA}=.053, \mathrm{SRMR}=.039$ 


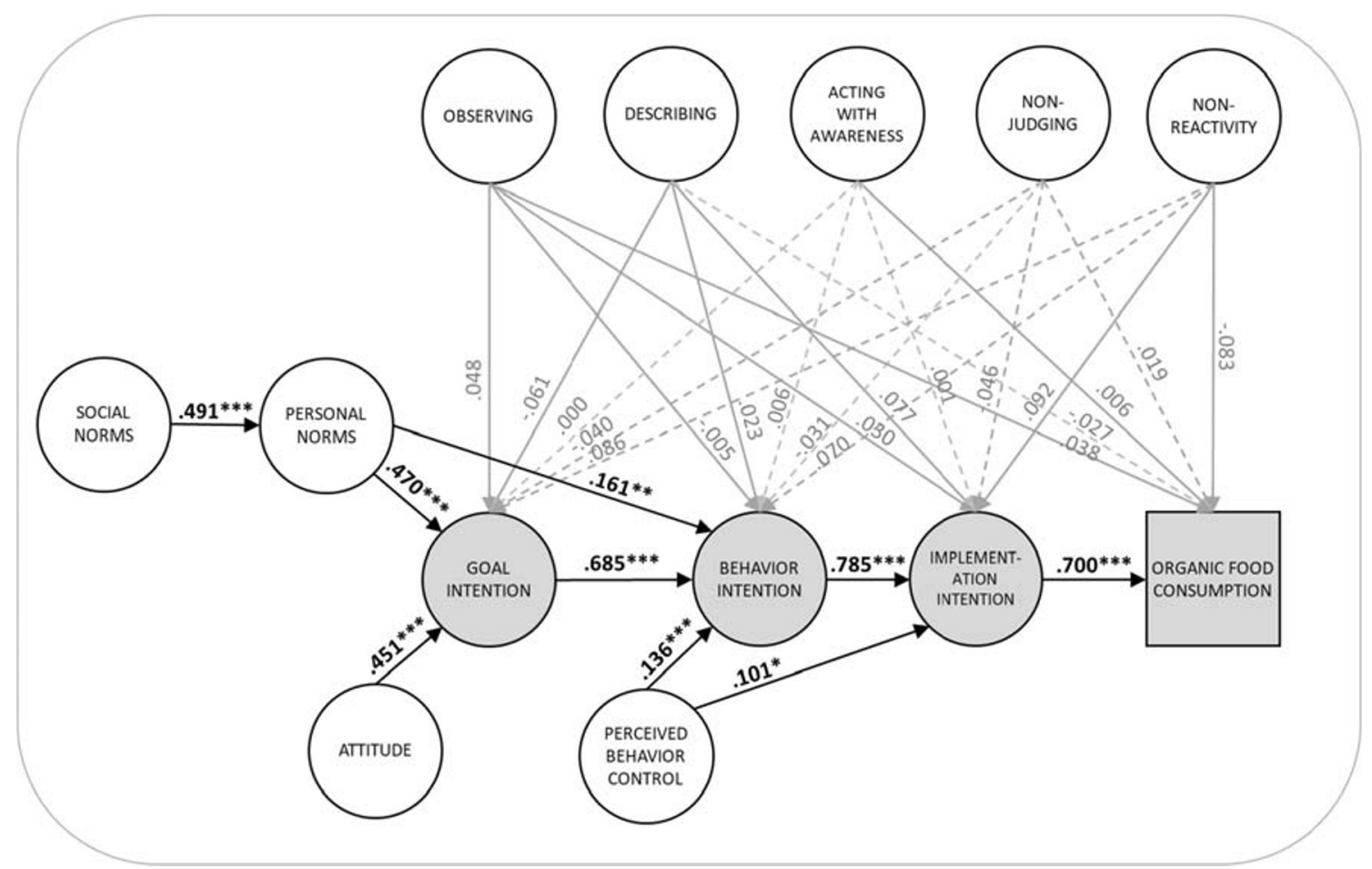

Fig. 3 Model 3: extended stage model with mindfulness facets as predictors of intentions and behavior. Note. Completely standardized coefficients. Dashed arrows = relationship was expected to be nonsignificant; continuous arrows $=$ relationship was expected to be

participants who stated at least a low intention to prefer organic foods, missing values occurred on those scales, especially in members of the preaction stage. This is consistent with the significant; bold lines $=$ significant relationships; $* p<.05 ; * * p<.01$; $* * * p<.001 ; N=560$; model fit (Satorra-Bentler correction): $\chi^{2}(502)=$ $969.028, p<.000 ;$ CFI $=.952$, TLI $=.944$, RMSEA $=.043$, $\mathrm{SRMR}=.051$

assumption that members of the preaction stage have no or a very low intention and, consequently, no or very low selfefficacy toward the behavior change. Therefore, the variables

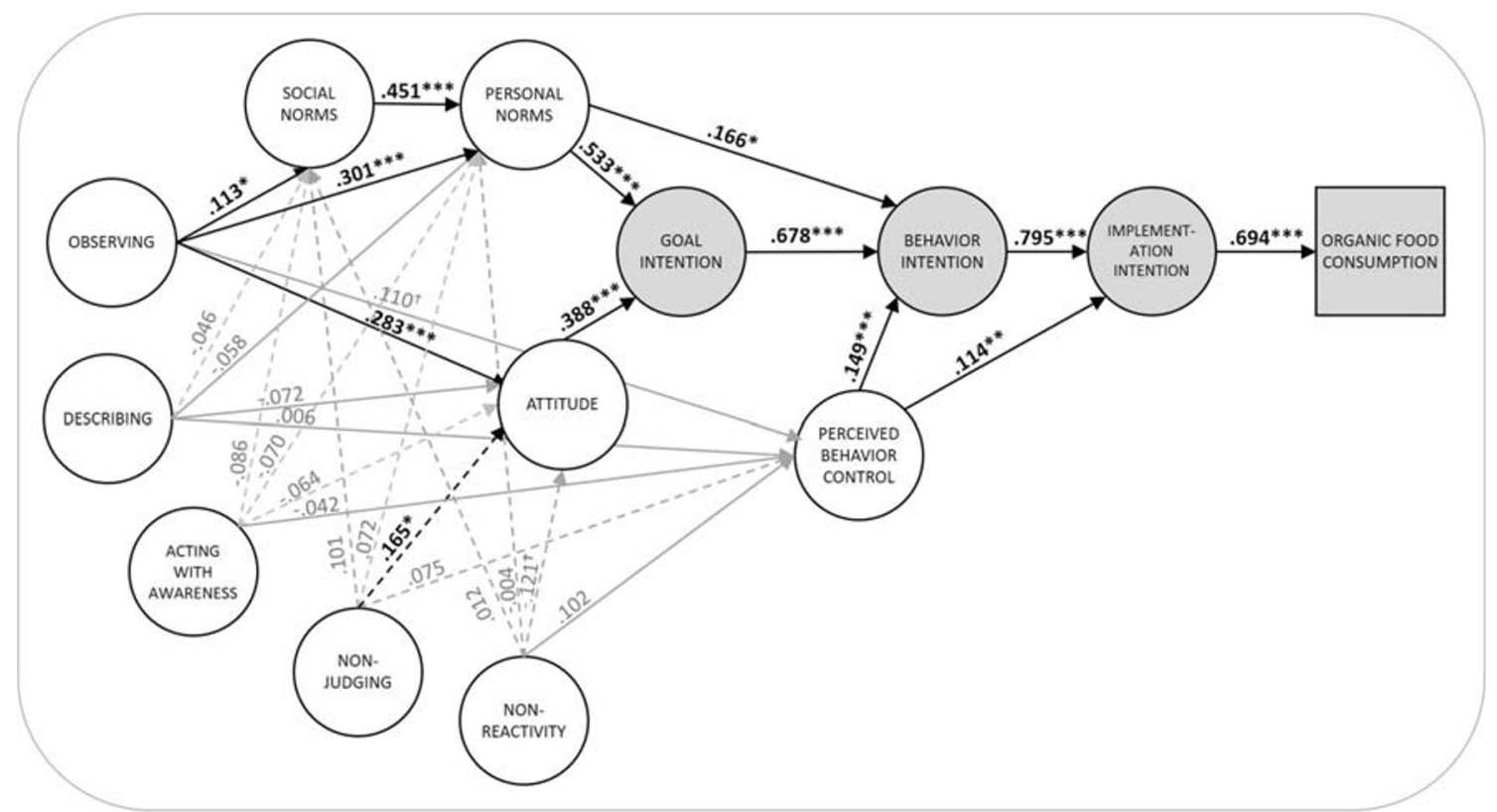

Fig. 4 Model 4: mindfulness and stage-specific variables. Note. Completely standardized coefficients. Dashed arrows = relationship was expected to be non-significant; continuous arrows = relationship was expected to be significant; bold lines $=$ significant relationships; $* p<.05$;
${ }^{* *} p<.01 ; * * * p<.001 ;{ }^{\mp} p<.100 ; N=560$; model fit (Satorra-Bentler correction): $\chi^{2}(517)=963.833, p<.000 ; \mathrm{CFI}=.954$, TLI $=.948$, RMSEA $=.041$, SRMR $=.046$ 
of maintenance and recovery self-efficacy were not included in the following SEM. The internal consistencies of all the measures ranged from satisfactory to good (see Table 3).

The SEM of the basic stage model (Fig. 2) showed a good fit $\left(\chi^{2}(77)=185.907, p<.000 ;\right.$ CFI $=.979$, TLI $=.971$, RMSEA $=.053$, SRMR $=.039$ ), which indicates a plausible model. The CFA with mindfulness revealed a broadly acceptable fit $\left(\chi^{2}(160)=444.654, p<.000 ; \mathrm{CFI}=.935\right.$, TLI $=.922$, $\mathrm{RMSEA}=.060, \mathrm{SRMR}=.053)$. To maintain comparability, and due to the lack of substantially theoretical reasons, we refrained from modifying the model. An ANOVA including the participants who provided information about their income $(N=289)$ revealed no significant differences in the per capita income of the members of different stages $(F(3,292)=0.65$, $p=.584)$

\section{Mindfulness, Intentions, and Organic Food Consumption}

The model 2, which included intentions and behaviors as dependent variables and the five mindfulness dimensions as predictors, revealed significant relationships between observing and goal intention $(\beta=.317, p<.000)$, between describing and goal intention $(\beta=-.119, p=.024)$ and between nonreactivity and implementation intention $(\beta=.102$, $p=.049)$. The model showed overall an acceptable fit $\left(\chi^{2}\right.$ $(292)=668.218, p<.000 ; \mathrm{CFI}=.948, \mathrm{TLI}=.938$, $\mathrm{RMSEA}=.051, \mathrm{SRMR}=.046)$. No significant relationships between the mindfulness dimensions and intentions remained in the model 3, where the stage-specific variables were included. This indicated that the relationships found in the previous model do not remain stable when the other stage variables are added (Q2.1). The overall fit of model 3 was broadly acceptable $\left(\chi^{2}(502)=969.028, p<.000\right.$; $\mathrm{CFI}=.952, \mathrm{TLI}=.944, \mathrm{RMSEA}=.043, \mathrm{SRMR}=.051)$. The changes in the explained variance in the different models are summarized in Tables 4. In model 3 (see Fig. 3), compared to the basic stage model, a small positive change in explained variance through the inclusion of mindfulness occurred in the goal intention $\left(\Delta R^{2}=.012\right)$ and the implementation intention $\left(\Delta R^{2}=.012\right)$.

\section{Mindfulness and Stage-Specific Predictors}

Model 4 tested the mindfulness dimensions as predictors of the stage-specific variables (see Fig. 4). It revealed positive relations between observing and social norms $(\beta=.157$, $p=.046)$, personal norms $(\beta=.301, p<.000)$, and attitude $(\beta=.283, p<.000)$. Further, a weak relationship between the non-judging facet and attitude $(\beta=.165, p=.024)$ was found. The model fit remained overall acceptable $\left(\chi^{2}(517)=\right.$ 963.833, $p<.000 ; \mathrm{CFI}=.954, \mathrm{TLI}=.948, \mathrm{RMSEA}=.041$, SRMR = .046). On the basis of model 4 , the following indirect effects were tested: (1) the indirect effect of observing on personal norms, mediated by social norms, (2) the indirect effect of observing on goal intention, mediated by personal norms, (3) the indirect effect of observing on goal intention, mediated by attitude, and (4) the indirect effect of non-judging on goal intention, meditated by attitude. All of the tested indirect effects were significant, noticeable through a

Table 2 Mean differences of the stage variables in different stages

\begin{tabular}{|c|c|c|c|c|c|}
\hline Stage variable & $\begin{array}{l}\text { Predecision } \\
N=104(18.6 \%) \\
M(\mathrm{SD})\end{array}$ & $\begin{array}{l}\text { Preaction } \\
N=157(28 \%) \\
M(\mathrm{SD})\end{array}$ & $\begin{array}{l}\text { Action } \\
N=128(22.9 \%) \\
M(\mathrm{SD})\end{array}$ & $\begin{array}{l}\text { Postaction } \\
N=171(30.5 \%) \\
M(\mathrm{SD})\end{array}$ & $\begin{array}{l}\text { ANOVA } \\
F\end{array}$ \\
\hline Goal intention ${ }^{1}$ & $1.82(0.82)$ & $3.32(0.81)$ & $3.65(0.68)$ & $4.30(0.64)$ & $236.37 * * *$ \\
\hline Behavior intention & $1.58(0.81)$ & $2.74(0.92)$ & $3.34(0.87)$ & $4.10(0.76)$ & $207.7 * * *$ \\
\hline Implementation intention $^{1}$ & $1.43(0.83)$ & $2.07(1.03)$ & $3.06(1.09)$ & $3.36(1.31)$ & $98.00 * * *$ \\
\hline Organic food consumption $(\mathrm{OFC})^{1}$ & $1.96(0.89)$ & $2.47(0.67)$ & $2.73(0.54)$ & $3.41(0.72)$ & $84.48 * * *$ \\
\hline Social norm & $2.08(0.97)$ & $2.68(1.01)$ & $2.82(1.01)$ & $3.16(0.97)$ & $26.27 * * *$ \\
\hline Personal norm & $1.71(0.83)$ & $3.14(1.01)$ & $3.61(0.97)$ & $4.10(0.91)$ & $146.7 * * *$ \\
\hline Attitude $^{1}$ & $2.90(1.09)$ & $3.96(0.75)$ & $4.23(0.66)$ & $4.57(0.59)$ & $76.66 * * *$ \\
\hline \multirow[t]{2}{*}{$\mathrm{PBC}$} & $3.07(0.96)$ & $2.81(0.78)$ & $3.31(0.77)$ & $3.81(0.84)$ & $41.97 * * *$ \\
\hline & $N=36$ & $N=131$ & $N=120$ & $N=169$ & \\
\hline \multirow[t]{2}{*}{ Maintenance self-efficacy } & $3.03(0.84)$ & $3.02(0.72)$ & $3.50(0.78)$ & $3.87(0.77)$ & $35.21 * * *$ \\
\hline & $N=36$ & $N=131$ & $N=120$ & $N=168$ & \\
\hline Recovery self-efficacy $^{1}$ & $2.71(0.87)$ & $3.76(0.79)$ & $4.08(0.70)$ & $4.45(0.65)$ & $54.00 * * *$ \\
\hline
\end{tabular}

${ }^{1}$ A significant Levene test indicated the violation of variance homogeneity; therefore, the $\mathrm{F}$ value and significance of the welch test are reported Note. Items for maintenance and recovery self-efficacy were not presented to participants that stated no behavior intention. Therefore, especially in the lower stages, missings occurred

$* * * p<.001$ 


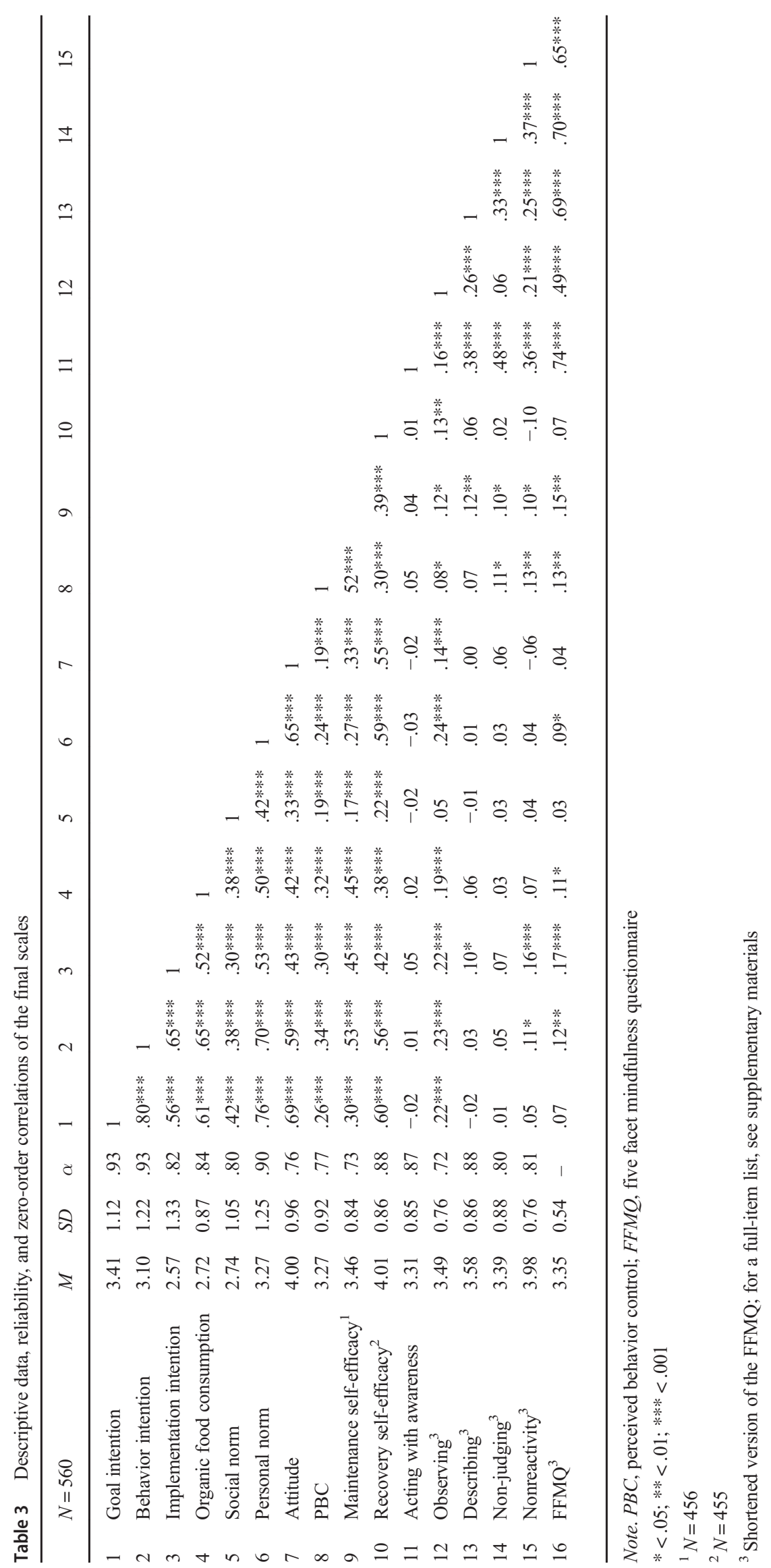


Table 4 Comparison of the explained variance in dependent variables in the different models

\begin{tabular}{llllll}
\hline Dependent variable & $\begin{array}{l}\text { Model 1: basic } \\
\text { stage model } \\
R^{2}\end{array}$ & $\begin{array}{l}\text { Model 3 } \\
R^{2}\end{array}$ & $\begin{array}{l}\text { Change in } R^{2} \\
\text { Model 4 }\end{array}$ & \multicolumn{2}{c}{ Change in $R^{2}$} \\
\hline Goal intention & .762 & .770 & .012 & .762 & .000 \\
Behavior intention & .764 & .768 & .004 & .767 & .003 \\
Implementation intention & .713 & .725 & .012 & .715 & .002 \\
Organic food consumption & .481 & .480 & .001 & .482 & .001 \\
Personal norm & .233 & .241 & .008 & .321 & .108 \\
Social norm & & & & .019 & - \\
Attitude & & & & .081 & - \\
Perceived behavior control & & & & .036 & - \\
\hline
\end{tabular}

Note. $\Delta R^{2}$, difference in the explained variance compared to model 1 (basic stage model) confidence interval above zero (see Table 5). Compared to the basic stage model (model 1, see Fig. 2), the inclusion of the mindfulness facets caused a considerable increase in the explained variance in the personal norm $\left(\Delta R^{2}=.108\right.$, see Table 4).

\section{Mindfulness Differences Between Stage Members}

The comparison of the different stage groups in terms of the mindfulness dimensions yielded an overall significant difference in the dimension observing $(F(3,556)=4.61, p=.003)$, with a small main effect for stage membership $\left(\eta^{2}=.02,95 \%\right.$ CI $[.004 ; .053], f=.16)$. The post hoc test revealed a significant medium-sized mean difference $\left(p=.002, d_{\text {cohen }}=.43\right)$ of observing between the stage of predecision $(M=3.29)$ and postaction $(M=3.64)$. Further, in the post hoc tests, nonjudging was significantly different $\left(p=.034, d_{\text {cohen }}=.32\right)$ in the preaction $(M=3.31)$ and postaction $(M=3.51)$ stages (see Table 6).

\section{Discussion}

The present study successfully applied a stage model on organic food consumption behavior, integrated the facets of dispositional mindfulness, and systematically tested the relationships between mindfulness and stage variables. The empirical analysis suggests two main findings. First, consistent across all analyses, the mindfulness facet of observing was found to be particularly relevant. Second, mindfulness does not function as a direct predictor of intentions and organic food consumption behavior when directly compared to the stage-specific predictors in the models 2 and 3. However, as an indirect predictor, mindfulness and specifically the facet of observing has an indirect connection with the goal intention toward organic food consumption in model 4. Overall, the results confirm mindfulness as a distal predictor for pro-environmental behavior. To investigate the associated mechanisms and starting points for promoting pro-environmental behavior through mindfulness, a further investigation of the observing facet would be beneficial.
Table 5 Bootstrap confidence intervals of the indirect effects in model 4

\begin{tabular}{llllll}
\hline & Indirect effects & Boot estimate & \multirow{2}{*}{ Boot SE } & \multicolumn{2}{l}{ 95\% CI } \\
\cline { 5 - 6 } & & & & Boot LL & Boot UL \\
\hline 1. & Observing $\rightarrow$ personal norm $\rightarrow$ goal intention & .286 & .074 & .141 & .430 \\
& Total effect & .336 & .084 & .172 & .500 \\
2. & Observing $\rightarrow$ social norm $\rightarrow$ personal norm & .204 & .058 & .090 & .318 \\
& Total effect & .814 & .155 & .511 & 1.117 \\
3. & .202 & .058 & .090 & .315 \\
Observing $\rightarrow$ attitude $\rightarrow$ goal intention & .253 & .085 & .087 & .419 \\
Total effect & Non-judging $\rightarrow$ attitude $\rightarrow$ goal intention & .082 & .038 & .007 & .158 \\
$\quad$ Total effect & .063 & .050 & -.034 & .161 \\
\hline
\end{tabular}

Note. Unstandardized estimates. 95\% CI, bias-adjusted confidence interval with lower and upper limit; $S E$, standard error; Boot, bootstrap; $N=5.000$; LL, lower limit; UL, upper limit 
Table 6 Mean differences between the stages on the mindfulness dimensions

\begin{tabular}{|c|c|c|c|c|c|}
\hline Mindfulness dimension & $\begin{array}{l}\text { Predecision } \\
N=104(18.6 \%) \\
M(\mathrm{SD})\end{array}$ & $\begin{array}{l}\text { Preaction } \\
N=157(28 \%) \\
M(\mathrm{SD})\end{array}$ & $\begin{array}{l}\text { Action } \\
N=128(22.9 \%) \\
M(\mathrm{SD})\end{array}$ & $\begin{array}{l}\text { Postaction } \\
N=171(30.5 \%) \\
M(\mathrm{SD})\end{array}$ & $\begin{array}{l}\text { ANOVA } \\
F\end{array}$ \\
\hline Acting with awareness & $3.33(0.92)$ & $3.24(0.86)$ & $3.35(0.78)$ & $3.34(0.86)$ & 0.54 \\
\hline Observing & $3.31(0.80)$ & $3.44(0.74)$ & $3.53(0.78)$ & $3.64(0.72)$ & $4.61 * *$ \\
\hline Describing $^{1}$ & $3.69(0.79)$ & $3.44(0.95)$ & $3.55(0.84)$ & $3.67(0.82)$ & $2.24^{\mathrm{T}}$ \\
\hline Non-judging & $3.42(0.91)$ & $3.24(0.90)$ & $3.41(0.89)$ & $3.51(0.85)$ & $2.64^{\mathrm{T}}$ \\
\hline Nonreactivity & $2.93(0.81)$ & $2.97(0.75)$ & $3.04(0.79)$ & $3.00(0.72)$ & 0.53 \\
\hline
\end{tabular}

Note. $*<.05 ; * *<.01 ;{ }^{\mp}<.100$

${ }^{1}$ A significant Levene test indicated the violation of variance homogeneity; therefore, the $F$ value and significance of the welch test are reported for describing

\section{Relationships Between Mindfulness Facets, Intentions, and Organic Food Consumption}

The test of the relationship between mindfulness, intentions, and organic food consumption in the reduced stage model (model 2) shows a direct connection between observing and goal intention. Even though this relationsship is not stable, when the complete stage model is included, it might indicate that observing is connected with the development of a general goal intention toward organic food consumption. A greater sensitivity toward one's experiences through mindful observation may constitute a greater basis for reflection and value clarification (Shapiro et al. 2006) as well as meaning in life (Garland et al. 2015). This in turn can be seen as a basis to develop a goal intention that is consistent with one's general life goals. Second, the items of observing include aspects of perception of the natural environment (i.e., "I pay attention to sensations, such as the wind in my hair or sun on my face."). This could point to the relevance of the direct awareness of natural environments to engage in pro-environmental behaviors, specifically food consumption. Future studies should consider variables such as connectedness to nature that are directly related to the natural environment and, at the same time, predictors of pro-environmental behaviors (Barbaro and Pickett 2016; Mayer and Frantz 2004). Since nature connectedness is also a source of happiness (Zelenski and Nisbet 2014), research on this pathway is promising. Further, in the reduced stage model (model 2), nonreactivity showed a positive but weak connection with the implementation intention. Nonreactivity is a central dimension of mindfulness that is relevant for emotion regulation strategies (Desrosiers et al. 2014), and helps to control impulsive acting toward food consumption (Keesman et al. 2017; Park and Dhandra 2017). The relationship between nonreactivity and the implementation intention suggests that nonreactivity might go along with a planned implementation process. Further experimental studies could focus on the role of nonreactivity in breaking habits with regard to pro-environmental behavior. A weak significant negative relationship between describing and the goal intention occurred unexpectedly in model 2 . At this point, no post hoc explanation seems plausible, and, thus, we refrain from drawing conclusions with respect to our hypotheses. It should also be noted that the describing facet is not usually seen as a core element of the tradistional concept of mindfulness in Buddhisn and that the assessment of the ability to describe feelings with words in the context of mindfulness might be especially difficult (Grossman and van Dam 2011). Further, the relationships between the mindfulness facets and the intentions (model 2) do not remain significant when the stagespecific variables are included (model 3). This highlights the limitations of mindfulness as a direct predictor of intentions and organic food consumption behavior when directly compared to the predictive value of personal and social norms, attitudes, and perceived behavior control. A comparison of the model 3 with the basic stage model shows that the mindfulness aspects contribute no substantial explained variances in intentions or behaviors. This is in line with the assumption that mindfulness is a distal predictor of pro-environmental behavior.

\section{Relationships Between Mindfulness and Stage-Specific Variables}

The analysis of mindfulness aspects and the stage-specific variables revealed relationships of observing with the social and personal norms as well as with attitude. At this point, indirect effects of observing on goal intention and personal norm were identified. First, personal norms mediated the connection between observing and goal intention. This may indicate that observing in this context might be related to reflective processes, which in return result in a personal obligation toward the preference of organic food or a sustainable lifestyle in general. With regard to personal norms, meaning in life and different sources of meaning (Schnell 2011; Steger et al. 2006), life goals, and values (Unanue et al. 2016) could potentially explain the mechanism of this relationship and should 
be addressed in future studies. Second, a positive attitude toward the preference of organic food mediated the relationship between observing and goal intention. According to the TPB, a positive attitude toward a behavior is developed through the evaluation of perceived benefits or disadvantages as well as the outcome expectations of certain behaviors (Ajzen 1991). With regard to organic food consumption, especially beliefs about health benefits, better taste and environmental concerns are strong predictors for a positive attitude toward organically grown foods (Aertsens et al. 2009; Michaelidou and Hassan 2008). Moreover, a heightened mindful awareness toward internal and external stimuli goes along with health orientation and health behavior in general (Geiger et al. 2018b). Further, due to the sensitization of one's senses through mindful observing (Hong et al. 2014), high observing might also go along with a higher demand for good taste and enjoyment of food. Therefore, a positive attitude toward organic food seems more likely, as people tend to expect the taste of organic food to be superior compared to conventional food (Hughner et al. 2007). Overall, to investigate the role of observing for attitude and goal intention at a deeper level, health orientations as well as beliefs about the taste of organic food could be valuable. Third, an indirect effect of observing on personal norm, mediated by social norm, was identified. Since a higher ability to observe internal and external stimuli may also be connected to the salience of social norms, a positive relationship between observing and social norms is plausible. At this point, in further studies, a distinction between descriptive and injunctive social norms or global and local social norms could be valuable in understanding the mechanism (Kormos et al. 2015; Vesely and Klöckner 2018). Fourth, an indirect effect of non-judging on goal intention, mediated by attitude, occurred unexpectedly. As nonjudging involves a non-evaluative stance toward thoughts and feelings, a direct connection to any intention does not seem plausible. According to the present results, people who judge their thoughts less have higher goal intention toward organic food consumption. One explanation could be that those not distracted by negative thoughts or rumination develop a goal intention more easily than those who do not. In fact, a decrease in rumination is considered one of the central mechanisms of mindfulness (Svendsen et al. 2017). A closer look at the suggested paradoxes of mindfulness as well as mechanisms such as reperceiving could be valuable to understand this relationship (Shapiro et al. 2006; Shapiro et al. 2018).

In model 4 , the gain in the explained variance through mindfulness is quite low. This indicates a limited value of mindfulness to explain the factors that influence the purchase of organic foods and should be noted with regard to the interpretation of the present results. One exception is that the explained variance in personal norms grew substantial when mindfulness was included. This might demonstrate the potential of mindfulness to go along with a moral obligation toward organic food consumption. With reference to the different suggested pathways from mindfulness to sustainable consumption (Geiger et al. 2018a; Hunecke and Richter 2019), this result suggets the role of mindfulness to go along with personal values that are connected to organic food consumption.

\section{Differences in Mindfulness Aspects in Stages of Organic Food Consumption}

As expected, the mindfulness aspect of observing was significantly higher in members of the postaction stage than in those of other stages. This may indicate that observing, or the degree to which people notice internal and external experiences, can be relevant in successfully passing the stages toward acquiring the new behavior of organic food consumption. This is in line with the theoretical assumptions of the stages and intervention recommendations of the SSBC. While in the stage of predecision, the enhancement of awareness and self-focus is central (Bamberg et al. 2011), and people in the stage of postaction have already processed through these steps and have higher levels of observing as a consequence. A significant mean difference was unexpectedly found in the dimension of non-judging between people in the preaction and postaction stages, indicating that those in the preaction stage were more judgmental toward their thoughts and feelings. A post hoc interpretation may be that this is due to the reflective and uncertain nature of the preaction stage, in which people want to change their behavior but are not yet sure how to achieve this goal.

\section{Limitations and Future Research}

The cross-sectional design of the study does not allow causal conclusions regarding the impact of mindfulness on organic food consumption intentions and behavior. The design also limits the reliability of the mediation analyses, and this can lead to biased estimates in single cross-sectional studies (Maxwell and Cole 2007). Future studies can collect data from (quasi-) experimental designs to address questions of causal mechanisms between mindfulness and pro-environmental behaviors. While data were collected conscientiously in selected communities to reach a broad spectrum of people with regard to the assumed stages of action, it is not representative but a convenience sample, which limits the generalizability of the results.

We successfully applied a modified version of the SSBC to organic food consumption and tested the plausibility of the theoretical model analyzing mean differences and using SEM. However, the high intercorrelations between the intentions indicated similarity of the different intentions even though the indicators for multicollinearity (variance inflation factor) and the fit indices were within the common limits. Although we included central stage-specific predictors and 
the most important variables with regard to organic food consumption, not all the predictors suggested in the original model were controlled. This could have led to different results in relation to the mindfulness aspects. Further, the assessment of pro-environmental behaviors using self-reports is an adequate and commonly used approach, but it can still involve validity problems with regard to actual behavior (Kormos and Gifford 2014). The stage model has a focus on the process of behavior change that is marked by four different stages. We used the categorization in the stages to examine the differences between the participants in terms of to mindfulness to gain additional information beyond the stage variables. However, in terms of the assumed stages, it was not possible to proof the stability of the stage or stage progression over time due to the cross-sectional study design. For this purpose, longitudinal studies are required, and the stage model approach would be useful to track the changes in specific behaviors from one stage to another.

The focus of the present study was on the preference of organic food consumption, because it is a central part of a sustainable lifestyle in terms of ecological impact. However, there are further potential motivators that we have not directly considered in our model, such as beliefs about health benefits and better taste of organically grown foods (Aertsens et al. 2009). Furthermore, other ecologically relevant fields of action such as mobility, energy conservation have to be investigated to fully estimate the potential of mindfulness to foster a sustainable lifestyle. The identification of the relevant mindfulness aspects in relation to stage-specific variables is helpful for planning future (quasi-) experimental studies. In the present study, observing showed the strongest relationships with social and personal norms and attitude. To further investigate this relationship, a look at conceptual close psychological constructs such as self-awareness (Vago and Silbersweig 2012) could be useful. Further, the aspect of observing can be distinguished in inner and outer awareness (Bergomi et al. 2015). Since mindfulness is often used as an umbrella term for various concepts and meditation practices, a consistent definition or measurement is not identifiable in the present research literature (Van Dam et al. 2018). It should be noted that we assessed self-attributed mindfulness with a questionnaire in a sample with mostly non-meditators in this study. It is very likely that selfreported mindfulness has limited similarity with the experience of mindfulness practice, and the interpretation of the items varies in meditator and non-meditator samples (Grossman and van Dam 2011). For instance, in a study by Baer et al. (2008) using the FFMQ, the observing facet varied in its connection with psychological symptoms in meditator and non-meditator student samples. Therefore, the results of the present study may be different in a meditator sample. Moreover, the study does not allow conclusions regarding the potential of mindfulness meditation to promote pro-environmental behavior. The results of the present study can only be interpreted in terms of the specific measurement used. Although the shortened version of the FFMQ used was largely proofed regarding its construct validity in a previous study (Hunecke and Richter 2019), a short version can limit the comparability. While the use of a multidimensional instrument prevents the derivation of an extremely simplified understanding of mindfulness, some aspects of mindfulness are still missing, especially paradoxes of mindfulness and its practice, such as acceptance vs. change and effort vs. non-striving (Shapiro et al. 2018), and they are not adequately assessed with the common instruments. The focus on the five different aspects of mindfulness is beneficial to understand the relevant aspects of mindfulness for organic food consumption and the stage-specific variables. The present study, therefore, offers useful recommendations for future studies. However, when it comes to the practice of mindfulness, the complete separation of these aspects is not beneficial, owing to the interactions between the different mindfulness dimensions (Desrosiers et al. 2014). To ensure the benefits for emotion regulation of mindfulness meditation, the aspect of observing should not be trained in isolation but always along with a non-judging stance (Baer et al. 2008; Iani et al. 2019).

Data Availability Statement Data and supplementary materials are available at the Open Science Framework (https://osf.io/gfb5q).

Author Contributions NR: Designed the study, collected data, analyzed data, and wrote the manuscript.

MH: Contributed ideas regarding the theoretical approach, the study design and supported in revision of the manuscript.

Funding Information Open Access funding provided by Projekt DEAL.

\section{Compliance with Ethical Standards}

Conflict of Interest The authors declare that they have no conflict of interest.

Ethical Approval All procedures performed in studies involving human participants were in accordance with the ethical standards of the institutional research committee of the Ruhr-University Bochum (Faculty of Psychology, Case No. 392) and with the 1964 Helsinki declaration and its later amendments or comparable ethical standards.

Informed Consent Informed consent was obtained from all individual participants included in the study.

Open Access This article is licensed under a Creative Commons Attribution 4.0 International License, which permits use, sharing, adaptation, distribution and reproduction in any medium or format, as long as you give appropriate credit to the original author(s) and the source, provide a link to the Creative Commons licence, and indicate if changes were made. The images or other third party material in this article 
are included in the article's Creative Commons licence, unless indicated otherwise in a credit line to the material. If material is not included in the article's Creative Commons licence and your intended use is not permitted by statutory regulation or exceeds the permitted use, you will need to obtain permission directly from the copyright holder. To view a copy of this licence, visit http://creativecommons.org/licenses/by/4.0/.

\section{References}

Aertsens, J., Verbeke, W., Mondelaers, K., \& van Huylenbroeck, G. (2009). Personal determinants of organic food consumption: A review. British Food Journal, 111(10), 1140-1167. https://doi.org/10. 1108/00070700910992961

Ajzen, I. (1991). The theory of planned behavior. Organizational Behavior and Human Decision Processes, 50(2), 179-211. https:// doi.org/10.1016/0749-5978(91)90020-T

Amel, E. L., Manning, C. M., \& Scott, B. A. (2009). Mindfulness and sustainable behavior: Pondering attention and awareness as means for increasing green behavior. Ecopsychology, 1(1), 14-25. https:// doi.org/10.1089/eco.2008.0005

Arch, J. J., Brown, K. W., Goodman, R. J., Della Porta, M. D., Kiken, L. G., \& Tillman, S. (2016). Enjoying food without caloric cost: The impact of brief mindfulness on laboratory eating outcomes. Behaviour Research and Therapy, 79, 23-34. https://doi.org/10. 1016/j.brat.2016.02.002

Baer, R. A., Smith, G. T., Hopkins, J., Krietemeyer, J., \& Toney, L. (2006). Using self-report assessment methods to explore facets of mindfulness. Assessment, 13(1), 27-45. https://doi.org/10.1177/ 1073191105283504

Baer, R. A., Smith, G. T., Lykins, E., Button, D., Krietemeyer, J., Sauer, S., Walsh, E., Duggan, D., \& Williams, J. M. G. (2008). Construct validity of the five facet mindfulness questionnaire in meditating and nonmeditating samples. Assessment, 15(3), 329-342. https://doi. org $/ 10.1177 / 1073191107313003$

Bahl, S., Milne, G. R., Ross, S. M., Mick, D. G., Grier, S. A., Chugani, S. K., Chan, S. S., Gould, S., Cho, Y.-N., Dorsey, J. D., Schindler, R. M., Murdock, M. R., \& Boesen-Mariani, S. (2016). Mindfulness: Its transformative potential for consumer, societal, and environmental well-being. Journal of Public Policy \& Marketing, 35(2), 198-210. https://doi.org/10.1509/jppm.15.139

Bamberg, S. (2013a). Applying the stage model of self-regulated behavioral change in a car use reduction intervention. Journal of Environmental Psychology, 33, 68-75. https://doi.org/10.1016/j. jenvp.2012.10.001

Bamberg, S. (2013b). Changing environmentally harmful behaviors: A stage model of self-regulated behavioral change. Journal of Environmental Psychology, 34, 151-159. https://doi.org/10.1016/j. jenvp.2013.01.002

Bamberg, S., Fujii, S., Friman, M., \& Gärling, T. (2011). Behaviour theory and soft transport policy measures. Transport Policy, 18(1), 228-235. https://doi.org/10.1016/j.tranpol.2010.08.006 .

Barbaro, N., \& Pickett, S. M. (2016). Mindfully green: Examining the effect of connectedness to nature on the relationship between mindfulness and engagement in pro-environmental behavior. Personality and Individual Differences, 93, 137-142. https://doi.org/10.1016/j. paid.2015.05.026

Barrett, B., Grabow, M., Middlecamp, C., Mooney, M., Checovich, M. M., Converse, A. K., Gillespie, B. \& Yates, J. (2016). Mindful climate action: Health and environmental co-benefits from mindfulness-based behavioral training. Sustainability, 8(10). https://doi.org/ $10.3390 /$ su8101040.
Bengstsson, J., Ahntström, J., \& Weibull, A.-C. (2005). The effects of organic agriculture on biodiversity and abundance: A meta-analysis. Journal of Applied Ecology, 42(2), 261-269. https://doi.org/10. 1111/j.1365-2664.2005.01005.x .

Bergomi, C., Tschacher, W., \& Kupper, Z. (2015). Meditation practice and self-reported mindfulness: A cross-sectional investigation of meditators and non-meditators using the comprehensive inventory of mindfulness experiences (CHIME). Mindfulness, 6(6), 14111421. https://doi.org/10.1007/s12671-015-0415-6 .

Bishop, S. R. (2004). Mindfulness: A proposed operational definition. Clinical Psychology: Science and Practice, 11(3), 230-241. https://doi.org/10.1093/clipsy/bph077 .

Brown, K. W., \& Kasser, T. (2005). Are psychological and ecological well-being compatible? The role of values, mindfulness, and lifestyle. Social Indicators Research, 74(2), 349-368. https://doi.org/ 10.1007/s11205-004-8207-8

Cook, J., Oreskes, N., Doran, P. T., Anderegg, W. R. L., Verheggen, B., Maibach, E. W., Carlton, J. S., Lewandowsky, S., Skuce, A. G., Green, S. A., Nuccitelli, D., Jacobs, P., Richardson, M., Winkler, B., Painting, R., \& Rice, K. (2016). Consensus on consensus: A synthesis of consensus estimates on human-caused global warming. Environmental Research Letters, 11(4), 48002. https://doi.org/10. 1088/1748-9326/11/4/048002

de Bruin, E. I., Topper, M., Muskens, J. G. A. M., Bögels, S. M., \& Kamphuis, J. H. (2012). Psychometric properties of the five facets mindfulness questionnaire (FFMQ) in a meditating and a nonmeditating sample. Assessment, 19(2), 187-197. https://doi.org/10. $1177 / 1073191112446654$

Desrosiers, A., Vine, V., Curtiss, J., \& Klemanski, D. H. (2014). Observing nonreactively: A conditional process model linking mindfulness facets, cognitive emotion regulation strategies, and depression and anxiety symptoms. Journal of Affective Disorders, 165, 31-37. https://doi.org/10.1016/j.jad.2014.04.024

Ericson, T., Kjønstad, B. G., \& Barstad, A. (2014). Mindfulness and sustainability. Ecological Economics, 104, 73-79. https://doi.org/ 10.1016/j.ecolecon.2014.04.007

Faul, F., Erdfelder, E., Lang, A.-G., \& Buchner, A. (2007). G*Power 3: A flexible statistical power analysis program for the social, behavioral, and biomedical sciences. Behavior Research Methods, 39(2), 175191. https://doi.org/10.3758/BF03193146 .

Fischer, D., Stanszus, L., Geiger, S., Grossman, P., \& Schrader, U. (2017). Mindfulness and sustainable consumption: A systematic literature review of research approaches and findings. Journal of Cleaner Production, 162, 544-558. https://doi.org/10.1016/j.jclepro.2017. 06.007 .

Garland, E. L., Farb, N. A., Goldin, P., \& Fredrickson, B. L. (2015). Mindfulness broadens awareness and builds eudaimonic meaning: A process model of mindful positive emotion regulation. Psychological Inquiry, 26(4), 293-314. https://doi.org/10.1080/ 1047840X.2015.1064294

Geiger, S., Fischer, D., Schrader, U. \& Grossman, P. (2019). Meditating for the planet: Effects of a mindfulness-based intervention on sustainable consumption behaviors. Environment and Behavior, 001391651988089 . https://doi.org/10.1177/0013916519880897.

Geiger, S., Grossman, P., \& Schrader, U. (2018a). Mindfulness and sustainability: Correlation or causation? Current Opinion in Psychology, 28, 23-27. https://doi.org/10.1016/j.copsyc.2018.09. 010 .

Geiger, S., Otto, S., \& Schrader, U. (2018b). Mindfully green and healthy: An indirect path from mindfulness to ecological behavior. Frontiers in Psychology, 8, 2306. https://doi.org/10.3389/fpsyg.2017.02306

Gollwitzer, P. M. (1990). Action phases and mind-sets. In R. M. Sorrentino \& E. T. Higgins (Eds.), Handbook of motivation and cognition: Foundations of social behavior (pp. 53-92). Guilford Press. 
Grossman, P., \& van Dam, N. T. (2011). Mindfulness, by any other name...: Trials and tribulations of sati in western psychology and science. Contemporary Buddhism, 12(1), 219-239. https://doi.org/ 10.1080/14639947.2011.564841

Hong, P. Y., Lishner, D. A., \& Han, K. H. (2014). Mindfulness and eating: An experiment examining the effect of mindful raisin eating on the enjoyment of sampled food. Mindfulness, 5(1), 80-87. https://doi. org/10.1007/s12671-012-0154-x .

Hu, L.-t. \& Bentler, P. M. (1999). Cutoff criteria for fit indexes in covariance structure analysis: Conventional criteria versus new alternatives. Structural Equation Modeling: A Multidisciplinary Journal, 6(1), 1-55. https://doi.org/10.1080/10705519909540118.

Hughner, R. S., McDonagh, P., Prothero, A., Shultz, C. J., \& Stanton, J. (2007). Who are organic food consumers? A compilation and review of why people purchase organic food. Journal of Consumer Behaviour, 6(2-3), 94-110. https://doi.org/10.1002/cb.210.

Hunecke, M. (2013). Psychological resources for sustainable lifestyles. A report from Denkwerk Zukunft - Foundation for cultural renewal. Bonn: Denkwerk Zukunft. https://www.denkwerkzukunft.de/ downloads/reportpsychologicalresources.

Hunecke, M. (2018). Psychology of sustainability - Psychological resources for sustainable lifestyles. In O. Parodi \& K. Tamm (Eds.), Routledge studies in sustainability. Personal sustainability: Exploring the far side of sustainable development (pp. 33-50). Routledge.

Hunecke, M., \& Richter, N. (2019). Mindfulness, construction of meaning and sustainable food consumption. Mindfulness, 10(3). https:// doi.org/10.1007/s12671-018-0986-0 .

Iani, L., Lauriola, M., Chiesa, A., \& Cafaro, V. (2019). Associations between mindfulness and emotion regulation: The key role of describing and nonreactivity. Mindfulness, 10(2), 366-375. https://doi. org/10.1007/s12671-018-0981-5 .

Jacob, J., Jovic, E., \& Brinkerhoff, M. B. (2009). Personal and planetary well-being: Mindfulness meditation, pro-environmental behavior and personal quality of life in a survey from the social justice and ecological sustainability movement. Social Indicators Research, 93(2), 275-294. https://doi.org/10.1007/s11205-008-9308-6 .

Kabat-Zinn, J. (1990). Full catastrophe living: Using the wisdom of your body and mind to face stress, pain, and illness. Bantam Books.

Kasser, T. (2006). The high price of materialism. MIT Press.

Keesman, M., Aarts, H., Häfner, M., \& Papies, E. K. (2017). Mindfulness reduces reactivity to food cues: Underlying mechanisms and applications in daily life. Current Addiction Reports, 4(2), 151-157. https://doi.org/10.1007/s40429-017-0134-2 .

Kiken, L. G., Garland, E. L., Bluth, K., Palsson, O. S., \& Gaylord, S. A. (2015). From a state to a trait: Trajectories of state mindfulness in meditation during intervention predict changes in trait mindfulness. Personality and Individual Differences, 81, 41-46. https://doi.org/ 10.1016/j.paid.2014.12.044

Klöckner, C. A. (2017). A stage model as an analysis framework for studying voluntary change in food choices. The case of beef consumption reduction in Norway. Appetite, 108, 434-449. https://doi. org/10.1016/j.appet.2016.11.002

Kormos, C., \& Gifford, R. (2014). The validity of self-report measures of proenvironmental behavior: A meta-analytic review. Journal of Environmental Psychology, 40, 359-371. https://doi.org/10.1016/j. jenvp.2014.09.003

Kormos, C., Gifford, R., \& Brown, E. (2015). The influence of descriptive social norm information on sustainable transportation behavior. Environment and Behavior, 47(5), 479-501. https://doi.org/10.1177/ 0013916513520416 .

Kristeller, J., Wolever, R. Q. \& Sheets, V. (2014). Mindfulness-Based Eating Awareness Training (MB-EAT) for binge eating: A randomized clinical trial. Mindfulness, 5(3), 282-297. https://doi.org/10. 1007/s12671-012-0179-1.
Lilja, J. L., Lundh, L.-G., Josefsson, T., \& Falkenström, F. (2013). Observing as an essential facet of mindfulness: A comparison of FFMQ patterns in meditating and non-meditating individuals. Mindfulness, 4(3), 203-212. https://doi.org/10.1007/s12671-0120111-8

Maxwell, S. E., \& Cole, D. A. (2007). Bias in cross-sectional analyses of longitudinal mediation. Psychological Methods, 12(1), 23-44. https://doi.org/10.1037/1082-989X.12.1.23

Mayer, F. S., \& Frantz, C. M. (2004). The connectedness to nature scale: A measure of individuals' feeling in community with nature. Journal of Environmental Psychology, 24(4), 503-515. https://doi. org/10.1016/j.jenvp.2004.10.001 .

Michaelidou, N., \& Hassan, L. M. (2008). The role of health consciousness, food safety concern and ethical identity on attitudes and intentions towards organic food. International Journal of Consumer Studies, 32(2), 163-170. https://doi.org/10.1111/j.1470-6431.2007. 00619.x .

Michalak, J., Zarbock, G., Drews, M., Otto, D., Mertens, D., Ströhle, G., Schwinger, M., Dahme, B., \& Heidenreich, T. (2016). Erfassung von Achtsamkeit mit der deutschen Version des Five Facet Mindfulness Questionnaires (FFMQ-D). Zeitschrift Für Gesundheitspsychologie, 24(1), 1-12. https://doi.org/10.1026/ 0943-8149/a000149.

Pachauri, R. K., \& Mayer, L. (Eds.). (2015). Climate change 2014: Synthesis report. Contribution of Working Groups I, II and III to the Fifth Assessment Report of the Intergovernmental Panel on Climate Change.

Panno, A., Giacomantonio, M., Carrus, G., Maricchiolo, F., Pirchio, S., \& Mannetti, L. (2018). Mindfulness, pro-environmental behavior, and belief in climate change: The mediating role of social dominance. Environment and Behavior, 50(8), 864-888. https://doi.org/10.1177/ 0013916517718887

Papies, E. K., Barsalou, L. W., \& Custers, R. (2012). Mindful attention prevents mindless impulses. Social Psychological and Personality Science, 3(3), 291-299. https://doi.org/10. $1177 / 1948550611419031$

Park, H. J., \& Dhandra, T. K. (2017). Relation between dispositional mindfulness and impulsive buying tendency: Role of trait emotional intelligence. Personality and Individual Differences, 105, 208-212. https://doi.org/10.1016/j.paid.2016.09.061 .

Pepping, C. A., O'Donovan, A., \& Davis, P. J. (2013). The positive effects of mindfulness on self-esteem. The Journal of Positive Psychology, 8(5), 376-386. https://doi.org/10.1080/17439760. 2013.807353

Reisch, L., Eberle, U., \& Lorek, S. (2013). Sustainable food consumption: An overview of contemporary issues and policies. Sustainability: Science, Practice and Policy, 9(2), 7-25. https:// doi.org/10.1080/15487733.2013.11908111 .

Rosenberg, E. L. (2004). Mindfulness and consumerism. In T. Kasser \& A. D. Kanner (Eds.), Psychology and consumer culture: The struggle for a good life in a materialistic world (pp. 107-126). American Psychological Association.

Scalco, A., Noventa, S., Sartori, R., \& Ceschi, A. (2017). Predicting organic food consumption: A meta-analytic structural equation model based on the theory of planned behavior. Appetite, 112, 235-248. https://doi.org/10.1016/j.appet.2017.02.007

Schnell, T. (2011). Individual differences in meaning-making: Considering the variety of sources of meaning, their density and diversity. Personality and Individual Differences, 51(5), 667-673. https://doi.org/10.1016/j.paid.2011.06.006 .

Schwartz, S. H. (1977). Normative influences on altruism.Advances in Experimental Social Psychology, 10(1), 221-279.https://doi.org/10. 1016/S0065-2601(08)60358-5

Scialabba, N. E.-H., \& Müller-Lindenlauf, M. (2010). Organic agriculture and climate change. Renewable Agriculture and Food Systems, 25(02), 158-169. https://doi.org/10.1017/S1742170510000116 . 
Shapiro, S., Carlson, L. E., Astin, J. A., \& Freedman, B. (2006). Mechanisms of mindfulness. Journal of Clinical Psychology, 62(3), 373-386. https://doi.org/10.1002/jclp.20237 .

Shapiro, S., Siegel, R., \& Neff, K. D. (2018). Paradoxes of mindfulness. Mindfulness, 9(6), 1693-1701. https://doi.org/10.1007/s12671-0180957-5 .

Sivanathan, N., \& Pettit, N. C. (2010). Protecting the self through consumption: Status goods as affirmational commodities. Journal of Experimental Social Psychology, 46(3), 564-570. https://doi.org/ 10.1016/j.jesp.2010.01.006 .

Steger, M. F., Frazier, P., Oishi, S., \& Kaler, M. (2006). The meaning in life questionnaire: Assessing the presence of and search for meaning in life. Journal of Counseling Psychology, 53(1), 80-93. https://doi. org/10.1037/0022-0167.53.1.80 .

Svendsen, J. L., Kvernenes, K. V., Wiker, A. S., \& Dundas, I. (2017). Mechanisms of mindfulness: Rumination and self-compassion. Nordic Psychology, 69(2), 71-82. https://doi.org/10.1080/ 19012276.2016.1171730

Unanue, W., Vignoles, V. L., Dittmar, H., \& Vansteenkiste, M. (2016). Life goals predict environmental behavior: Cross-cultural and longitudinal evidence. Journal of Environmental Psychology, 46, 10 22. https://doi.org/10.1016/j.jenvp.2016.02.001 .

Vago, D. R., \& Silbersweig, D. A. (2012). Self-awareness, self-regulation, and self-transcendence (S-ART): A framework for understanding the neurobiological mechanisms of mindfulness. Frontiers in Human Neuroscience, 6, 296. https://doi.org/10.3389/fnhum.2012. 00296 .

Van Dam, N. T., van Vugt, M. K., Vago, D. R., Schmalzl, L., Saron, C. D., Olendzki, A., Meissner, T., Lazar, S. W., Kerr, C. E., Gorchov, J., Fox, K. C. R., Field, B. A., Britton, W. B., Brefczynski-Lewis, J. A., \& Meyer, D. E. (2018). Mind the hype: A critical evaluation and prescriptive agenda for research on mindfulness and meditation. Perspectives on Psychological Science: A Journal of the Association for Psychological Science, 13(1), 36-61. https://doi. org/10.1177/1745691617709589 .

Vermeulen, S. J., Campbell, B. M. \& Ingram, J. S. (2012). Climate change and food systems. Annual Review of Environment and Resources, 37(1), 195-222. https://doi.org/10.1146/annurev-environ-020411130608.

Vesely, S., \& Klöckner, C. A. (2018). Global social norms and environmental behavior. Environment and Behavior, 50(3), 247-272. https://doi.org/10.1177/0013916517702190

Visted, E., Vøllestad, J., Nielsen, M. B., \& Nielsen, G. H. (2015). The impact of group-based mindfulness training on self-reported mindfulness: A systematic review and meta-analysis. Mindfulness, 6(3), 501-522. https://doi.org/10.1007/s12671-014-0283-5 .

Von Koerber, K., Bader, N., \& Leitzmann, C. (2017). Wholesome nutrition: An example for a sustainable diet. The Proceedings of the Nutrition Society, 76(1), 34-41. https://doi.org/10.1017/ S0029665116000616.

Wang, J., Geng, L., Schultz, P. W., \& Zhou, K. (2019). Mindfulness increases the belief in climate change: The mediating role of connectedness with nature. Environment and Behavior, 51(1), 3-23. https://doi.org/10.1177/0013916517738036

Zelenski, J. M., \& Nisbet, E. K. (2014). Happiness and feeling connected. Environment and Behavior, 46(1), 3-23. https://doi.org/10.1177/ 0013916512451901

Publisher's Note Springer Nature remains neutral with regard to jurisdictional claims in published maps and institutional affiliations. 